\title{
Effect of the Probe Size and Interaction Volume on Quantitative X-ray Maps across Interfaces of a $\mathrm{Cu}-\mathrm{Al}$ Roll Bonded Laminate
}

\author{
Hendrix Demers ${ }^{1}$, Richard Wuhrer ${ }^{2}$, Ken Moran $^{3}$ and Raynald Gauvin ${ }^{1}$ \\ 1. Department of Mining and Materials Engineering, McGill University, Montreal, Quebec, Canada. \\ 2. Advanced Materials Characterisation Facility, University of Western, Sydney, NSW, Australia. \\ 3. Moran Scientific Pty Ltd, Bungonia, NSW, Australia.
}

Metal laminates have experienced rapid development in functional and high performance engineering applications. These laminated materials generally possess enhanced mechanical properties, leading to improved service performance. Roll bonding is recognized as an effective method in the manufacture of metal laminates. In the roll bonding process, the metals are first bonded under appropriate rolling conditions. Sintering heat treatments are then applied to the bonded metals to enhance their bond strength. The atomic movement of the metallic elements, across the interfacial areas, was analyzed via compositional profile and x-ray mapping analyses. The distribution of the metallic elements and the developments of the various metallic phases were identified and their effects on the property development of the metal laminate were studied.

High quality $\mathrm{x}$-ray maps were acquired at $20 \mathrm{keV}, 30^{\circ}$ takeoff angle, of a $\mathrm{Cu}-\mathrm{Al}$ roll bonded metal laminate after sintering at $430^{\circ} \mathrm{C}$ for 1.5 hours. $\mathrm{Al}, \mathrm{CuAl}_{2}, \mathrm{CuAl}, \mathrm{Cu}_{9} \mathrm{Al}_{4}$, and $\mathrm{Cu}$ phases were identified. A probe size of $0.7 \mu \mathrm{m}$ was used. Figure 1 shows the composition profile for each element and the total concentration versus position across the interface with standards based corrected quantification. The secondary electron image line profile (yellow line Fig. 1), shows a $\mathrm{CuAl}_{2}$ layer $6.5 \mu \mathrm{m}$ thick adjacent to the pure Aluminium. At this boundary, there is an electron interaction volume effect [1], which when ZAF corrected, produces an anomaly in the results. There is an increase in the Al concentration caused by an over-correction of the $\mathrm{Al}$ absorption correction factor due to the $\mathrm{Cu} \mathrm{L}$ absorption edge. At this interface, half of the electrons generate only $\mathrm{Al}$ x-rays, while the other half generate $\mathrm{Al}$ and $\mathrm{Cu} \mathrm{X}$-rays. The correction model assumes that the volume is a homogeneous $\mathrm{Cu}-\mathrm{Al}$ phase. The $\mathrm{Cu} \mathrm{L}$ is assumed to have absorbed Al K x-rays in the two sides of the interface, and thus over-corrects, leading to a much larger $\mathrm{Al}$ concentration. Figure 2 shows the absorption and atomic number correction factor maps for $\mathrm{Al}$ and $\mathrm{Cu}$. The secondary fluorescence $(\mathrm{F})$ correction was small enough to be ignored for this system. In this example, $\mathrm{Cu}$ concentration was close to correct one, and the result was improved by calculating the Al concentration by difference (green line Fig. 1).

Figure 3 shows the simulated backscattered electron (BSE) yield line scan profile, across the $\mathrm{Cu}-\mathrm{Al}$ roll bonded metal laminate, with the same phases identified experimentally using Monte Carlo MC X-Ray software [2]. Because of the large interaction volume and probe size, the BSE yield decreases close to the interface if the phase is a lower mean atomic number. Inversely, the BSE yield increases for phases with larger mean atomic number [3]. This effect can also introduce a correction error during the analysis. In this work, the quantification by k-ratio method near a phase boundary is studied using experimental and simulated intensities. Using Monte Carlo simulations, a ZA correction, which takes into account the probe size and interaction volume near an interface, is developed. Also, a model for BSE map generation using experimental concentrations is presented. This model will be used with the real BSE image to improve the correction factor used in the quantification. 


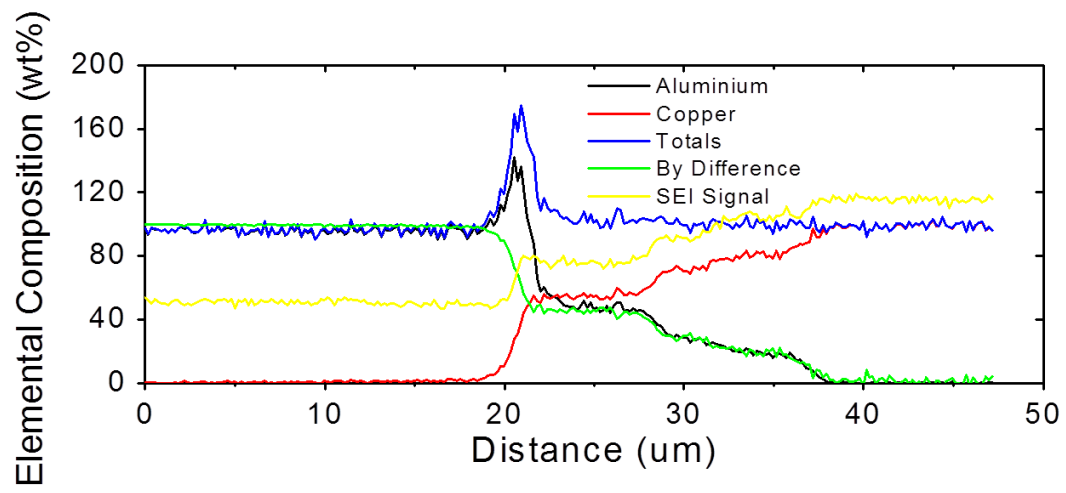

Figure 1. Experimental composition profile for $\mathrm{Al}, \mathrm{CuAl}_{2}, \mathrm{CuAl}, \mathrm{Cu}_{9} \mathrm{Al}_{4}$, and $\mathrm{Cu}$ phase boundary obtained by k-ratio quantification microanalysis with standards. From the total line (blue line), we can determine the interaction volume, including the beam size to be approximately $2 \mu \mathrm{m}$.

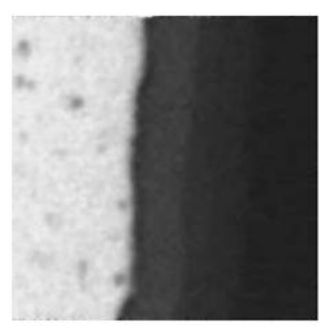

Aluminium Absorption (0.1 to 1$)$

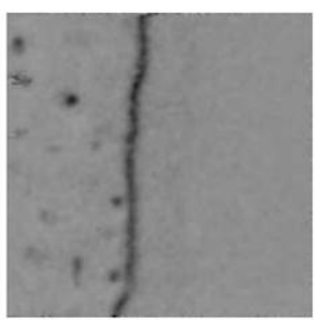

Copper Absorption (0.95 to 1$)$

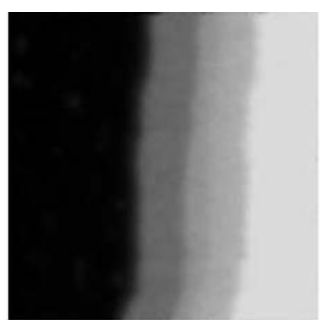

Aluminium $Z$ (1 to 1.2$)$

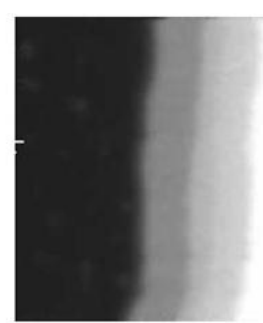

Copper Z

(0.8 to 1$)$

Figure 2. Absorption and atomic number correction factors map for a $\mathrm{Cu}-\mathrm{Al}$ roll bonded metal laminate [4]. Darkest pixel is lowest number, brightest pixel is highest number. A value of 1 represents no correction. However, a deviation from 1 is the magnitude of the correction. From left to right, in each $\mathrm{Al}$ phase, the $\mathrm{Al}$ absorption (A) factor varies from 1 to 0.355 to 0.296 to 0.26 , while the $\mathrm{Al}$ atomic number (Z) factor varies from 1 to 1.08 to 1.11 to 1.14 .

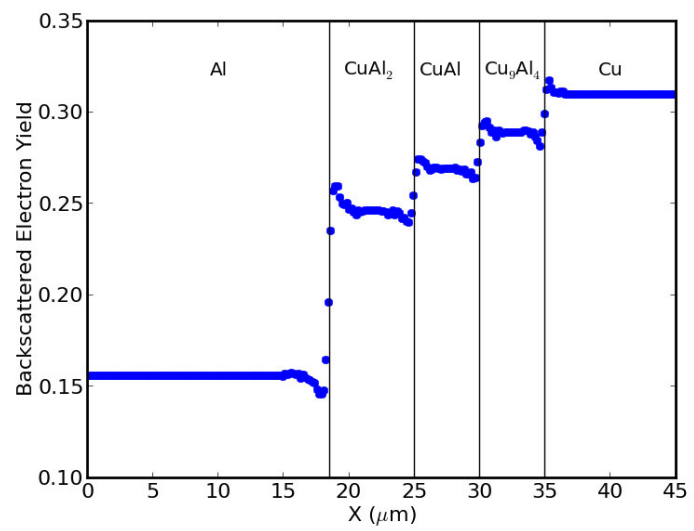

Figure 3. Simulated backscattered electron (BSE) yield line scan profile of a Cu-Al roll bonded metal laminate. The BSE variations observed are caused by the large interaction volume and probe size.

\section{References:}

[1] J. E. Mueller, J. W. Gillespie and S. G. Advani, Scanning, Early View (2012).

[2] R. Gauvin and P. Michaud, Microscopy and Microanalysis, 15 (2009), pp. 488-489.

[3] A. C. D. Riccardis, P. G. Merli, M. Nacucchi and L. Tapfer, Mikrochimica Acta 114-115 (1994), pp. 261-266.

[4] R. Wuhrer, M. Lee, K. Moran and W. Y. Yeung, Materials Forum, 30, (2006), pp. 225-232. 